University of New Hampshire

University of New Hampshire Scholars' Repository

Languages, Literatures, and Cultures

Scholarship

Languages, Literatures, and Cultures

$3-1-2000$

\title{
Evaluating intermediate Spanish students' speaking skills through a taped test: A pilot study
}

Lina Lee

University of New Hampshire, Durham, lina.lee@unh.edu

Follow this and additional works at: https://scholars.unh.edu/lang_facpub

Part of the Spanish and Portuguese Language and Literature Commons

Comments

Copyright (C) 2000 American Association of Teachers of Spanish and Portuguese. This article first appeared in Hispania 83:1 (2000), 127-138. Reprinted with permission by Johns Hopkins University Press.

\section{Recommended Citation}

Lee, Lina. Evaluating intermediate Spanish students' speaking skills through a taped test: A pilot study. Hispania, 83(1), 127-138, 2000. https://dx.doi.org/10.2307/346151

This Article is brought to you for free and open access by the Languages, Literatures, and Cultures at University of New Hampshire Scholars' Repository. It has been accepted for inclusion in Languages, Literatures, and Cultures Scholarship by an authorized administrator of University of New Hampshire Scholars' Repository. For more information, please contact Scholarly.Communication@unh.edu. 


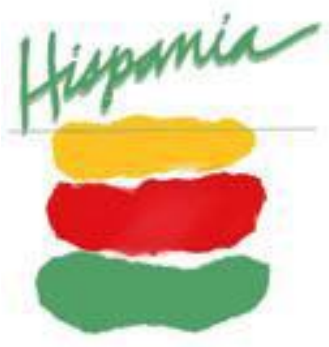

Evaluating Intermediate Spanish Students' Speaking Skills through a Taped Test: A Pilot Study

Author(s): Lina Lee

Source: Hispania, Vol. 83, No. 1 (Mar., 2000), pp. 127-138

Published by: American Association of Teachers of Spanish and Portuguese

Stable URL: http://www.jstor.org/stable/346151

Accessed: 30-05-2017 18:25 UTC

\section{REFERENCES}

Linked references are available on JSTOR for this article: http://www.jstor.org/stable/346151?seq=1\&cid=pdf-reference\#references_tab_contents You may need to $\log$ in to JSTOR to access the linked references.

JSTOR is a not-for-profit service that helps scholars, researchers, and students discover, use, and build upon a wide range of content in a trusted digital archive. We use information technology and tools to increase productivity and facilitate new forms of scholarship. For more information about JSTOR, please contact support@jstor.org.

Your use of the JSTOR archive indicates your acceptance of the Terms \& Conditions of Use, available at http://about.jstor.org/terms

American Association of Teachers of Spanish and Portuguese is collaborating with JSTOR to digitize, preserve and extend access to Hispania 


\title{
Evaluating Intermediate Spanish Students' Speaking Skills through a Taped Test: A Pilot Study
}

\author{
Lina Lee \\ University of New Hampshire
}

\begin{abstract}
A pilot study used the Spanish Oral Proficiency Test (SOPT) - a taped oral test to evaluate oral proficiency level of students of Intermediate Spanish. Based on the ACTFL Proficiency Guidelines (1986), the Intermediate-Mid was the appropriate level of oral proficiency for students at the end of two years of collegelevel language study. The study also examined what variables might affect the development of students' oral skills. The results showed that foreign language learning experience in academic settings or outside of class, such as study abroad and travel abroad, might affect students' overall speaking proficiency. In addition, linguistic inaccuracy from informal training may keep speakers to lower levels of proficiency. Learners should be more aware of the need to speak correctly to maintain a balance between function, content, and accuracy.
\end{abstract}

Key Words: ACTFL scales, taped oral proficiency test, intermediate Spanish, speaking skills, foreign language study

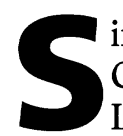

ince the publication of the American Council on the Teaching of Foreign Languages (ACTFL) Proficiency Guidelines in 1986, post-secondary foreign language programs have increasingly modified their curricula to emphasize the development of students' communicative skills. Assessing oral skills has become an essential part of foreign language acquisition as more and more foreign language programs adopt entrance and/or exit requirements that necessitate the evaluation of speaking skills. Both nationally and locally, establishing appropriate assessment tools has become a major effort. Researchers have employed the ACTFL oral proficiency interviews (OPI) (e.g., Magnan 1986, 1988, 1991; Moeller and Reschke 1993; Thompson 1996; Tschirner 1996). Ongoing discussions address such questions as (1) when and how to assess students' oral skills, (2) the level of proficiency that students should acquire at different stages of instruction, and (3) the criteria and procedures of rating that should be considered. In the light of the national discussion, this study focuses on the question: Is the ACTFL Intermediate-Mid level an appropriate requirement after two years of college-level language study?
The oral proficiency assessment described in this article was designed for the improvement of all levels of foreign language courses in a small public university in a rural area of the Northeast. The ACTFL Proficiency Guidelines (1986) were adapted as a model to establish appropriate checkpoints, discussed later in this article. The taped speaking test-Spanish Oral Proficiency Test (SOPT), which is not an OPIwas used to verify the expected proficiency levels of the checkpoints. These ratings, then, should not be considered equivalent to the OPI ratings.

This article first addresses the issue of oral proficiency testing and the rationale for a taped oral test. Second, the background of the study and the purposes of the study are described. Third, the development of testing materials and the instrument are described. Finally, the procedures, the results of this study, and implications of preliminary findings are discussed.

\section{Oral Proficiency Testing}

Omaggio defines "proficiency" as follows (1986):

Proficiency is a construct that enables us to define competence in a language in terms of (1) the functions 
one can carry out in the second language; (2) the contexts in which the language user can operate comfortably and adequately; and (3) the accuracy with which those various functions are carried out in a given context. (9)

Given the above competence, a proficiencybased assessment should focus on how well students actually use the language in reallife situations rather than what they know about it. A proficiency-based test should also allow students to use "functional" language skills and to express themselves creatively with the language in different contexts.

The OPI developed by ACTFL and Educational Testing Service (ETS) has been a stimulus for the creation of local proficiency-based assessment instruments (Byrnes and Canale 1987; Hill and Mosher 1988; Magnan 1985). The OPI, a standardized procedure for the "global" evaluation of oral skills, has been used to (1) place students in different courses, (2) fulfill foreign language requirements or major/minor requirements, (3) evaluate students' oral skills in specific courses, and (4) select students for study abroad programs (Fleak 1991). However, discussion continues regarding the practical problems of administration and scoring of the OPI in the foreign language classroom (Boyles 1994; Byrnes and Canale 1987; Cohen 1994; Galloway 1987; Halleck 1982; Lowe and Stansfield 1988). For instance, the amount of time and money involved in participating in the OPI workshop and becoming a certified rater has been the principal concern when adapting the OPI to assess students' oral skills (Hagiwara 1991). In addition, teachers may not have sufficient time to conduct the OPI with each individual, given the number of students enrolled in their classes each semester.

Other researchers argue that the OPI focuses too much on speech analysis at the sentence, rather than at the discourse, level (Kramsch 1986; Raffaldini 1988; Savignon 1985). Freed (1987) and VanPatten (1986) criticize the OPI for focusing too heavily on grammatical accuracy in the early developmental stages of language learning.
Bernhardt and Deville (1991) find the OPI "appropriate only under conditions whereby considerable instructional time has passed and whereby there is plenty of personnel time to conduct such an interview" (49).

Alternative and innovative formats of oral testing were subsequently created and developed. Examples are the Modified Oral Proficiency Interview (MOPI), developed by the Articulation and Achievement Project funded by the U.S. Department of Education for the Improvement of Postsecondary Education (Stansfield 1994), and the Simulated Oral Proficiency Interview (SOPI) (1994), a semi-direct tape-recorded speaking test. A study by Stansfield and Kenyon (1992) showed high correlation between the proficiency ratings given on the OPI and the SOPI. The Texas Oral Proficiency Test (TOPT) is another taperecorded proficiency test for teacher certification in Texas (Stansfield 1994).

Locally created speaking tests, criteria of oral assessment, and evaluation procedures based on the ACTFL Proficiency Guidelines and the actual OPI exist (e.g., the University of South Carolina, the University of Minnesota, and the University of Pennsylvania [Barnes, Klee, and Wakefield 1990; Freed 1987]). A number of improvements in these language programs followed implementation of the requirement for oral proficiency examinations apart from testing listening, reading, and writing skills. Students' attitudes toward language learning have improved as well (Barnes, Klee, and Wakefield 1990; Freed 1987; Villar and Meuser-Blincow 1993). Oral tests such as those described above aim primarily to assess students' overall speaking skills with the focus on "authentic communication."

\section{Rationale for Taped Oral Tests}

Educators have expressed concern about time and the expense involved in ACTFL certification for conducting the OPI in addition to using standardized procedures (Cohen 1994). Studies concerning the OPI have indicated the problems with 
rating reliability differences between the United States government's Interagency Language Roundtable (ILR) and ACTFL scales, oral proficiency levels related to length of instruction, and student background information (detailed in Tschirner and Heilenman 1998). Furthermore, not all instructors who give oral tests are properly trained or certified for oral proficiency interviews. According to Underhill (1987) and Shohamy (1998), a different assessment method needs to be considered to better understand the overall picture of oral proficiency. One such method is a taped test that is administered to a group.

A taped test of oral proficiency allows examinees to record their responses to a series of questions. In general, both testers and testees are given instructions about how to operate the tape recorder or language lab and use testing materials. A taped group test offers several advantages. First, a group-administered test allows examination of multiple students at a time, using standardized procedures. Second, it eliminates the need for having trained interviewers administer the test. Third, in view of the fact that speaking in front of people in a foreign language can provoke communication anxiety (Horwitz, Horwitz, and Cope 1991), taped tests are likely to cause less anxiety than face-to-face interviews. At the same time, other issues arise when using a taped oral test. In the absence of interaction between interviewer and interviewee, the latter does not have an opportunity to ask questions. Also, the oral taped test is probably not as spontaneous as a face-to-face interview. Nevertheless, a taped oral test based on the ACTFL Guidelines provides an alternative assessment method for measuring learners' oral skills.

\section{Background and Purposes of the Study}

The faculty of the Department of Foreign Language and Literature expressed interest in a proficiency-based requirement for major and minor students to replace the existing requirement of having accumulated a certain number of credit hours. The instructors were particularly interested in developing a workable outcomes assessment system to measure students' language skills and knowledge. In the fall of 1993, the Department reaffirmed its commitment to developing communicative skills, particularly oral proficiency. Proficiency-based instruction at the college focused on developing students' functional language skills. At the same time, the Department developed proficiency goals for four checkpoints in four areas of language skills-listening, speaking, reading, and writing-based on the ACTFL Proficiency Guidelines. The Guidelines were used as a framework for curriculum design, instructional objectives, and evaluation.

The four checkpoints were: (1) exit from the one-year language requirement for general education and for students majoring in education and seeking state teacher certification; (2) entry into the minor or major; (3) exit from the minor or continuing on into the major; and (4) exit from the major. These checkpoints are also used to verify students' progress throughout the program. In general, students who continue into the second year of language courses are considering the foreign language as a major or minor. Students usually declare their major or minor after the fourth-semester language course. A semester of study abroad is required of all majors and is highly recommended for minors.

The chair of the Department arranged general meetings to discuss a framework for the four checkpoints along with goals and assessment procedures. The expected proficiency level of the four skills which was subsequently established at each checkpoint was based on the ACTFL scales. For example, the desired proficiency level of speaking and writing for Checkpoint 2 at the end of the fourth semester is Intermediate Mid (IM), while an Intermediate High (IH) proficiency is expected for listening and reading skills.

Along with the goals for each checkpoint, both written and oral proficiency tests were developed. To identify the appropriate 
level of the oral proficiency for all four checkpoints, a taped oral test, the Spanish Oral Proficiency Test (SOPT), was given to different groups of students in Spring 1994 and Fall 1994. Students in first-, third-, and fourth-year Spanish voluntarily participated in the study, while students in intermediate Spanish were required to take the taped oral test as part of their final exam. It was hoped that through regular administration of the SOPT test, appropriate oral proficiency level for each of four checkpoints could be determined.

Since the researcher, the author of this article, was mainly involved in teaching second-year Spanish, the study focused on this level. The purposes of the study were (1) to determine whether Intermediate Mid was the appropriate level of oral proficiency for Checkpoint 2-entry into the major or minor, and (2) to examine what variables might affect the development of students' oral skills.

\section{Development of Testing Materials and Instrument}

The SOPT was designed during the fall of 1993 to serve as a standardized assessment procedure to measure overall oral proficiency across all levels. Based on the ACTFL Proficiency Guidelines, we assembled a test bank with a variety of questions at different levels, with three instructors collaborating in the writing of questions for the test. The process of establishing this particular oral proficiency test focused on each level of difficulty, defined as novice, intermediate, advanced, and superior. Four types of questions constituted the test:

(1) picture sequences: description of a series of drawings.

(2) giving directions: a pictorial map for giving directions between two points.

(3) topical discourse: selected topics with different discourse strategies, including a process, supporting an opinion, or talking about a hypothetical situation.

(4) situations: responding to a specific real-life situation.

Based on the information concerning the content and format of the SOPI from the Test Rater Training Manual written by the CAL-Central of Applied Linguistics (1994), a topical profile was created. The following list provides samples of topics and functions at different levels:

(1) Novice Level: name favorite food; list favorite classes.

(2) Intermediate Level: describe your family; describe your leisure activities; ask for information about a trip to Guatemala.

(3) Advanced Level: describe what you did last summer; explain the registration procedure at your school; give advice to a friend on study abroad.

(4) Superior Level: express your opinion on foreign language study in high school.

Three instructors reviewed the items using a four-point scale. The rating scale for each item ranged from "not adequate" to "very adequate" for the content validity as well as the level of difficulty. Before collecting the data for the study, reliability was verified through the test-retest procedure. Three forms (A, B, and C) of the test were developed and administrated to different groups of students in order to eliminate repetition and memorization of questions. Seventeen students received Form A; 14, Form $\mathrm{B}$; and 15, Form $\mathrm{C}$. Two raters scored the tests both times using the criteria based on the ACTFL Proficiency Guidelines. The test-retest reliability alpha coefficient with a five-week interval for Form $\mathrm{A}(\mathrm{N}=17)$ was .82 , for Form B $(\mathrm{N}=14)$ was .83 , and for Form $\mathrm{C}(\mathrm{N}=15)$ was .80 . All coefficients were significant at the .001 level.

Each test consisted of seven questions and a cover sheet with instructions. The following samples, along with the level of difficulty, are from Form A, on which the present study is based:

1. You are talking to your friend Oscar about some of your favorite places. Describe your favorite restaurant.

(Description in present * $\mathrm{IM}=$ intermediate level)

Describe tu restaurante favorito.

2. Tell us how to get from here 
(FEINBERG Library) to Champlain Valley Hall (CVH).

(Give directions * $\quad{ }^{*} \mathrm{IM}$ )

¿Nos puedes decir cómo llegar a CVH?

3. Give us a summary of a film or TV program that you saw recently.

(Give a brief summary * $\mathrm{ADV}=$ advanced level)

¿De qué trató la película que viste?

4. Give us your opinion about whether abortion should be legal in the U.S. level)

(Support an opinion $\quad{ }^{\mathrm{S} U P}=$ superior

¿Qué opinas sobre el aborto?

5. Describe to us what your family typically did during the summer when you were a teenager.

(Narration in past $\quad{ }^{*} \mathrm{ADV}$ )

¿Qué hacían tus parientes en el verano cuando tenías quince años?

\section{Method}

Subjects. A total of 30 students in the fourthsemester Spanish course (SPA 214) from different language backgrounds participated in the study. Table 1 illustrates the students' language background information. Most had completed three years of Spanish in high school and/or three semesters of Spanish in college. Five students had travel experience, and three had studied in a Spanish-speaking country. One student, born and raised in the Dominican Republic, was considered a true-native speaker, while two Puerto Rican students and one Colom- bian who spoke Spanish at home and used English in school and social settings were classified as non-true-native speakers. Students who were enrolled in the course (SPA 214) were taking Spanish as either their major or minor. They were required to take SPA 214 regardless of prior knowledge of Spanish.

Students enrolled in this course were expected to attain a minimum level of IM oral proficiency based on ACTFL guidelines by the end of the semester. Their teachers advised them to develop their communicative strategies and skills during the semester so that they would feel comfortable expressing their ideas in Spanish. Students received a copy of the ACTFL speaking guidelines to help them understand better the concept of "oral proficiency" and the kinds of functional skills they should possess to achieve the desired level of oral proficiency. Each week they met in three 50-minute class periods, in addition to a one-hour conversation class.

Procedure. Thirty students took the Spanish Oral Proficiency Test (SOPT) in the foreign language laboratory at the end of the semester as part of their final exam during the last week of class. The students received a packet of testing materials and completed a background information questionnaire. Students had approximately five minutes to read the instructions and prepare for recording. A total of 25 minutes was allotted for completing the test, to allow students enough time to respond to each question. With only seven questions to be answered in 25 minutes, students had ample time to

Table 1

Student Language Background Information

(Total $=30$ students)

\begin{tabular}{|c|c|c|c|c|}
\hline $\begin{array}{c}\text { High School } \\
\text { Study }\end{array}$ & $\begin{array}{l}1 \text { year } \\
2 \\
2\end{array}$ & $\begin{array}{l}2 \text { years } \\
5 \text { (17\%) }\end{array}$ & $\begin{array}{l}3 \text { years } \\
17(56 \%)\end{array}$ & $\begin{array}{c}\text { more than } 3 \text { years } \\
6(20 \%)\end{array}$ \\
\hline College Study & $\begin{array}{l}1 \text { semester } \\
0(0 \%)\end{array}$ & $\begin{array}{c}2 \text { semesters } \\
12(40 \%)\end{array}$ & $\begin{array}{c}3 \text { semesters } \\
16(53 \%)\end{array}$ & $\begin{array}{l}4 \text { semesters } \\
2(7 \%)\end{array}$ \\
\hline $\begin{array}{c}\text { Travel } \\
\text { Experience }\end{array}$ & $\begin{array}{c}\text { None } \\
25 \quad(84 \%)\end{array}$ & $\begin{array}{cl}2-3 & \text { months } \\
4 & (13 \%)\end{array}$ & $\begin{array}{c}6-9 \text { months } \\
1(3 \%)\end{array}$ & $\begin{array}{c}1 \text { year or more } \\
0(0 \%)\end{array}$ \\
\hline Study Abroad & $\begin{array}{c}\text { None } \\
27 \quad(90 \%)\end{array}$ & $\begin{array}{c}1 \text { summer } \\
1(3 \%)\end{array}$ & $\begin{array}{l}1 \text { semester } \\
2(7 \%)\end{array}$ & $\begin{array}{c}1 \text { year or more } \\
0(0 \%)\end{array}$ \\
\hline $\begin{array}{c}\text { Hispanic } \\
\text { Background }\end{array}$ & $26^{\text {None }}(87 \%)$ & $\begin{array}{l}\text { Puerto Rico } \\
2(7 \%)\end{array}$ & $\begin{array}{c}\text { Colombia } \\
1(3 \%)\end{array}$ & $\begin{array}{c}\text { Native Speaker } \\
1(3 \%)\end{array}$ \\
\hline
\end{tabular}


express themselves. Prompts were not recorded on the tape but were included in the test booklet. Once students had read the prompts in Spanish, they recorded their responses on the tape. Students were not allowed to erase any answers once they were recorded.

Evaluation. All tapes were labeled with the student's ID number and the course section. The evaluators received copies of the ACTFL Proficiency Guidelines (1986). Three had been trained to use the ACTFL Proficiency Guidelines during the semester, but they were not ACTFL certified. The researcher arranged meetings to discuss the Guidelines and the rating procedure, and asked the instructors to familiarize themselves with the Guidelines and rating criteria. Sample tapes of students from all levels of the pilot study had been duplicated so that the instructors could practice rating at home or in their offices, with other raters.

After listening to a set of sample tapes for practice, the instructors rated the proficiency level of each tape. They met several times during the semester to discuss the criteria set forth in the ACTFL Proficiency Guidelines. The instructors gave particular attention to samples that did not fit the profiles as described in the Guidelines. As a part of the preparation, the researcher discussed the results of the ratings and the rating criteria with a certified OPI tester and a Texas Oral Proficiency Test (TOPT) trainer. After these discussions, a rating system based on the descriptions of the ACTFL Guidelines was created. These criteria especially address the acceptable margin of difference within contiguous borders (i.e., Intermediate Mid and Intermediate High), and across a major border (i.e., from Intermediate to Advanced), as well as the major distinctions between Intermediate and Advanced levels of proficiency. The Advanced level stipulates the following functions:

(1) the ability to narrate, describe, and explain a situation
(2) the ability to handle communicative tasks in different time frames such as present, past, and future with a fair degree of accuracy

(3) the ability to use communication strategies to overcome shortcomings with a good flow of speech and adequate connected discourse

The Intermediate level is characterized by the following:

(1) the ability to participate in simple conversations on familiar topics

(2) the ability to handle uncomplicated tasks and often use learned elements and structures

(3) the ability to express oneself with limited vocabulary and linguistic accuracy

A crucial criterion was that the interviewee bordering between levels should demonstrate "characteristics of the next higher level at least 50 percent of the time" (Halleck 1996).

Thirty tapes made by intermediate Spanish students were evaluated for this study. Tapes were placed into six boxes with five tapes in each box. Each rater checked out one box at a time. Studies done by Barnwell (1991) and Halleck (1996) found paired ratings using trained raters to be a reliable and consistent procedure. Therefore, two trained instructors and the researcher evaluated all 30 tapes to ensure the fairness and accuracy of the evaluation. After listening to each tape, the rater assigned a global rating, using a form that indicated the strengths and weaknesses of each student interviewed. If two or more ratings were at the same level (IM), the final rating would be at that level (IM). Four tapes were sent to an ACTFL-certified OPI tester for arbitration. At the end of the evaluation period, the researcher arranged a final meeting, during which all three raters discussed the tapes that did not fit the profiles as described in the Guidelines in order to arrive at a final decision. 


\section{Results}

As illustrated in Table 2, two examinations were rated at $\mathrm{NH}$, five at IL, 17 at IM, five at $\mathrm{IH}$, and only one at ADV. same level (IL). Other disagreement among all three raters for one tape was from $\mathrm{NH}$ to IM. The ACTFL-certified OPI tester, therefore, evaluated this particular tape and rated it IL which was used as the final rating.

Table 2

Numbers and Percentage of Each Proficiency Level

(Total $=30$ students $)$

\begin{tabular}{|c|c|c|c|c|}
\hline $\begin{array}{l}\text { Novice } \\
\text { High }\end{array}$ & $\begin{array}{l}\text { Interm } \\
\text { Low }\end{array}$ & $\begin{array}{l}\text { Interm } \\
\text { Mid }\end{array}$ & $\begin{array}{l}\text { Interm } \\
\text { High }\end{array}$ & Advanced \\
\hline $2(6.7 \%)$ & $5(16.7 \%)$ & $17(56.6 \%)$ & $5(16.7 \%)$ & $1(3.3 \%)$ \\
\hline
\end{tabular}

All three evaluators rated one tape at the Advanced level, resulting in perfect interrater agreement at this level. Two of five tapes were rated IH by all three raters, while the other three were scored IH by two raters and IM by a third rater. The final rating was $\mathrm{IH}$, since two ratings were at the same level $(\mathrm{IH})$. Nine tapes received ratings at the IM level from all three raters, five a rating of IM from two evaluators, and one a rating of IL from one evaluator (Table 3 ). Interestingly, in three cases, raters disagreed completely, and, although their ratings ranged from IL to $\mathrm{IH}$, they did not cross a major threshold. Tapes with the disagreement between two adjoining sublevels went to all three raters as well as an ACTFLcertified OPI tester for review and evaluation. The ACTFL-certified OPI tester determined that the final rating should be IM.

Two tapes received a rating of IL from three raters. The first rater assigned one tape at $\mathrm{NH}$, while the second and third raters agreed on the IL. The final rating was assigned at IL since two ratings were at the
Finally, all three raters assigned one tape at the $\mathrm{NH}$ level, and the first rater and the third rater placed one tape at $\mathrm{NH}$, while the second rater disagreed on the rating by one adjoining sublevel-between NH and IL.

\section{Discussion and Implications}

More than $50 \%$ of the students were at the IM level of proficiency. The results seem to confirm that the desired level of Intermediate Mid oral proficiency was appropriate for Checkpoint 2 at the end of the fourth semester of Spanish courses, at least for this group of selected students. Data from the background sheet appear to suggest that several variables might affect the development of students' oral skills.

Foreign Language Experience Outside the Classroom. Only one student, a native speaker from the Dominican Republic, was rated at the Advanced level. The probable reason that the student did not receive the rating at the Superior level was because she

Table 3

Ratings at the Intermediate Mid Level

\begin{tabular}{|c|c|c|c|c|}
\hline Total $=17$ & Rater \#1 & Rater \#2 & Rater \#3 & Final Rating \\
\hline$\# 1=\# 9$ & IM & IM & IM & IM \\
\hline$\# 10$ & IM & IL & IM & IM \\
\hline$\# 11$ & IL & IM & IM & IM \\
\hline$\# 12$ & IM & IL & IM & IM \\
\hline$\# 13$ & IM & IM & IL & IM \\
\hline$\# 14$ & IL & IM & IM & IM \\
\hline$\# 15$ & IM & IL & IH & IM(OPI tester) \\
\hline$\# 16$ & IM & IL & IH & IM(OPI tester) \\
\hline$\# 17$ & IH & IL & IM & IM(OPI tester) \\
\hline
\end{tabular}


Foreign Language Experience Outside the Classroom and Oral Proficiency Level

\begin{tabular}{|c|c|c|}
\hline & Interm High = & Advanced = \\
\hline Native Speakers & $\begin{array}{c}\text { Dominican } \\
\text { Republic (1) }\end{array}$ \\
\hline Travel Experience & 9 months (1) & \\
\hline Study Abroad & 1 semester (1) & \\
\hline Hispanic Background & $\begin{array}{c}\text { Colombia (1) } \\
\text { Puerto Rico (2) }\end{array}$ & \\
\hline
\end{tabular}

had left the native environment at the age of ten. In addition, she did not show sufficient complexity in her background knowledge to answer the questions at the Superior level. After examining the backgrounds of the students who were rated at $\mathrm{IH}$, the results imply that contact with native speakers either at home or in a foreign country may be an important factor in reaching higher levels of oral proficiency. Two students who were rated at IH had the experience of traveling and/or studying abroad before taking Spanish in college. The other three who achieved an IH level came from Hispanic families, as stated previously-two from Puerto Rico and one from Colombia (Table 4).

As a result, students who had opportunities to use Spanish outside the classroom demonstrated their oral proficiency at the IH level by employing a variety of lexical items, common idiomatic expressions, and short connected discourse. Additional experiences, such as travel abroad, study abroad, or even living in an area where
Spanish is spoken, provide students with "real-life" situations in which they "use the target language to express, interpret and negotiate meaning with others" (Savignon 1983). Therefore, opportunities to use the language outside the classroom should be created to help students attain higher levels of language proficiency. Those who had no exposure to Spanish outside the classroom did not receive a rating higher than IM. As Judith E. Liskin-Gasparro and Kathryn Henry indicated in a 1994 presentation at Central States Conference on the Teaching of Foreign Languages, study and travel abroad may be crucial for students to acquire higher levels of oral proficiency.

Foreign Language Learning in Secondary Schools or Colleges. None of the students in this study was a "true beginner." Most had completed three years of Spanish in high school. Those students who had three years of Spanish in high school and three or four semesters in college received a rating of IM (Table 5).

Table 5

Foreign Language Study Schools and Ratings for Oral Proficiency Level

\begin{tabular}{|c|c|c|c|}
\hline $\begin{array}{c}\text { Proficiency } \\
\text { Level } \\
\text { Total }=30\end{array}$ & $\begin{array}{c}\text { Number of } \\
\text { Students }\end{array}$ & $\begin{array}{c}\text { Years of High } \\
\text { School }\end{array}$ & $\begin{array}{c}\text { Semesters of } \\
\text { College }\end{array}$ \\
\hline NH $=2$ & 2 & 3 & 3 \\
\hline IL $=5$ & 3 & 2 & 4 \\
\hline IM $=17$ & 2 & 3 & 3 \\
\hline & 8 & 3 & 4 \\
\hline & 5 & 3 & 3 \\
\hline IH $=5$ & 2 & 4 & 3 \\
\hline ADV $=1$ & 2 & 2 & 4 \\
\hline
\end{tabular}


The present study seems to confirm the findings of previous studies that most students after four semesters of college were rated at IM (Freed 1987; Magnan 1986; Tschirner 1992). However, based on the background information questionnaire, two students who had studied three years of Spanish in high school rated at the $\mathrm{NH}$ level. These students reported that the lack of hearing and speaking the language in high school had negatively affected their acquisition of functional language skills. They said they had not been encouraged to speak Spanish in class because the classes were taught mainly in English, but that their interest in Hispanic culture and people had motivated them to continue Spanish in college. Although they struggled with the communicative approach that encourages oral production, they seem to have realized, as Hall and Davis (1995) found, that "language learning was a difficult and timeconsuming process, requiring a substantial investment of energy" (30-31).

By contrast, one student, who had had only two years of Spanish in high school but had studied in Spain for one semester, was rated at $\mathrm{IH}$. The student said that what she found most valuable in learning Spanish in high school were the "stimulating" learning environment created by her teacher and the teacher's language ability. The student commented that the "communicative strategies" learned from her teacher were especially helpful in "getting her message across" while she was in Spain. Indeed, the ability to use communicative strategies is crucial in defining one's language proficiency (Canale and Swain 1980). One transfer student, who had studied Spanish three years in high school and two semesters in another college, was rated at IH. Describing his foreign language learning experience in college, the student mostly recalled the "interactive," "authentic," "cooperative," and "fun" activities in his small Spanish classes. He indicated that these activities required him to "use" Spanish. In summary, both the positive and negative learning experiences that students brought with them from previous schools might have affected their speaking skills in Spanish. Results also suggest that the type of language instruction and its effectiveness may be important variables that affect the development of oral skills.

\section{Aspects of Accuracy in Oral Proficiency} Interviews. The results showed that a total of $23.4 \%$ of the students were rated below IM (Table 2). The raters had a difficult time determining the proficiency level of two of the five students rated at (IL) because they did not fit the typical profile described in the ACTFL Guidelines (1986). These two students had exposure to Spanish only in the classroom context and performed at a "multi-level" function. The concept "multilevel" refers to "a contrast between high global task ability and content versus low accuracy and pronunciation" (Halleck 1996). Linguistic accuracy is considered one of the three substantial components of the OPI. Accuracy extends to five elements: pronunciation, vocabulary, grammar, fluency, and sociolinguistic competence (Marisi 1994). The raters ranked these special cases at IL because they felt that erroneous phonology and grammatical incorrectness gave rise to misunderstandings and prevented them from rating these students at IM.

$\mathrm{Ke}$ (1995) has argued that non-academic "street learners" of a second language often carry fossilized structures in their speech. Those who initially began their language training in non-academic setting are not aware of their errors when focusing on communication with native speakers. In addition, native speakers are not accustomed to correcting the speech errors of foreigners. Consequently, linguistic mistakes become enduring habits. The raters gave a proficiency level IM to a student who had lived in a Spanish-speaking neighborhood in New York City, based on the abundance of linguistic errors, such as inappropriateness of lexical items, incorrectness of syntax, and use of code-switches or regionalisms. Several researchers have brought "Regionalism" to the discussion of linguistic accuracy (Valdés 1989; Marisi 1994). Marisi (1994) 
showed that the less accurate speech was, the less tolerant the testers were of regionalisms. In the case of the student who had lived in New York, the raters might have viewed regionalisms as non-standard Spanish because they encountered some basic errors in the student's speech. Therefore, they rated this student at IM rather than IH. This student may not improve his speech without further instruction. This study seems to imply that it is important for students to develop accuracy over fluency at the Intermediate levels in order to avoid fossilization of the language.

\section{Summary and Recommendations for Future Study}

The present study proposed to find out whether Intermediate Mid would be the appropriate level for the oral proficiency goal of Checkpoint 2 at the end of the fourth semester of Spanish using a locally developed taped oral test. It also investigated factors that might influence students' oral proficiency. Although the sample size was small $(\mathrm{N}=30)$, the results of this study showed that students in this program tended to test at the Intermediate Mid level of speaking proficiency at the end of the fourth semester of Spanish at college level. Data from this study seem to support the idea that several variables, such as foreign language learning experience in academic settings or outside the classroom, might affect students' overall speaking proficiency. The learning environment, teaching methods, teachers' language ability, study abroad, and travel abroad had either a positive or a negative influence on learning outcomes. In addition, linguistic inaccuracy from informal training may keep speakers to lower levels of proficiency. Learners should be more aware of the need to speak correctly to maintain a balance between function, content, and accuracy.

While it is difficult to draw reliable conclusions about which variables affected test results, since only a few examples of each case appeared in this study, a number of important issues arise for future research beyond the scope of the study:

(1) In this study, only seven items were included in the test. Future study might be directed at investigating a wider range of speech samples to ascertain the effectiveness of oral taped testing and valid rating.

(2) Three non-ACTFL-certified raters were used in this study. Future research might determine whether substantial differences exist between the ratings of trained raters and ACTFL-certified raters.

(3) In this study, the SOPT was given to 30 students at the end of the fourth semester. Additional research might investigate the differences in oral proficiency level between the end of the fourth semester and the fifth semester.

(4) The sample for this study was 30 subjects from a small college. The results underscore the need for a follow-up study utilizing a larger number of subjects from different colleges in order to confirm the results of the study in general terms.

In conclusion, the study suggests that a taped oral test can be used as an alternative to measure students' oral skills, especially when no certified OPI tester is available, and that such a test can be successfully developed locally. Given the results of this study, it is clear that developing alternative means to assess students' oral skills using the ACTFL Proficiency Guidelines can be effective and respond to the programs of particular institutions.

\section{WORKS CITED}

American Council on the Teaching of Foreign Languages. 1986. ACTFL Proficiency Guidelines. Hastings-on-Hudson, NY: ACTFL.

Barnes, Betsy K., Carol A. Klee, and Ray M. Wakefield. 1990. "Reconsidering the FL Requirement: From Seat-Time to Proficiency in the Minnesota Experience." Challenges in the 1990's for College Foreign Language Programs. Issues in Language Program Direction. Ed. Sally S. Magnan. Boston: Heinle and Heinle. 59-69.

Barnwell, David. 1991. "Proficiency Testing and the Schools." Hispania 74.1: 187-89.

Bernhardt, Elizabeth B., and Craig Deville. 1991. "Testing in Foreign Language Programs and Testing Programs in Foreign Language Departments: Reflections and Recommendations." Assessing For eign Language Proficiency of Undergraduates. Issues 
in Language Program Direction. Ed. Richard V. Teschner. Boston: Heinle and Heinle. 43-59.

Boyles, Peggy. 1994. "Assessing the Speaking Skill in the Classroom: New Solutions to an Ongoing Problem." Teaching, Testing, and Assessment. Ed. Charles Hancock. Lincolnwood, IL: National Textbook Company. 87-110.

Byrnes, Heidi, and Michael Canale. 1987. "Introduction." Defining and Developing Proficiency: Guidelines, Implementations and Concepts. Ed. Heidi Byrnes and Michael Canale. Lincolnwood, IL: National Textbook Company. 1-4

Canale, Michael, and Merrill Swain. 1980. "Theoretical Bases of Communicative Approaches to Second Language Teaching and Testing." Applied Linguistics 1: 1-47.

Cohen, Andrew. 1994. Assessing Language Ability in the Classroom. Boston: Heinle and Heinle.

Fleak, Ken. 1991. "Using an Exit Requirement to Assess the Global Performance of Undergraduate Foreign Language Students." Assessing Foreign Language Proficiency of Undergraduates. Issues in Language Program Direction. Ed. Richard V. Teschner. Boston: Heinle and Heinle. 59-69.

Freed, Barbara. 1987. "Preliminary Impressions of the Effects of a Proficiency-Based Language Requirement." Foreign Language Annals 20: 139-46.

Galloway, Vicki. 1987. "From Defining to Developing Proficiency: A Look at the Decision." Defining and Developing Proficiency: Guidelines, Implementations and Concepts. Ed. Heidi Byrnes and Michael Canale. Lincolnwood, IL: National Textbook Company. 25-74.

Hagiwara, Peter. 1991. "Assessing the Problems of Assessment.” Assessing Foreign Language Proficiency of Undergraduates. Ed. Richard V. Teschner. Boston: Heinle and Heinle. 21-42.

Hall, Joan, and Jackie Davis. 1995. "Voices from the Traditional Classroom: Learner Reflections." Voices from the Field. Ed. Trisha Dvorak. Lincolnwood, IL: National Textbook Company. 132.

Halleck, Gene. 1982. “The Oral Proficiency Interview: Discrete Point Test or a Measure of Communicative Language Ability?" Foreign Language Annals 25: 227-31.

-. 1996. "Assessing Oral Proficiency: A Comparison of Holistic and Objective Measure." Modern Language Journal 79: 223-34.

Hill, David, and Art Mosher. 1988. "The Articulation of Curriculum through a Standardized ProficiencyBased Diagnostic/Placement Test: The USC Experience.” Dimension: Languages '88: 101-11.

Horwitz, Elaine K., Michael B. Horwitz, and Jo Ann Cope. 1991. "Foreign Language Classroom Anxiety." Language Anxiety: From Theory and Research to Classroom Implications. Ed. Elaine K. Horwitz and Dolly J. Young. Englewood Cliffs, NJ: PrenticeHall. 27-36.

Ke, Chuanre. 1995. "Aspects of Accuracy in a Proficiency-Oriented Program.” ADFL Bulletin 26:
29-35.

Kramsch, Claire. 1986. "From Language Proficiency to Interactional Competence." Modern Language Journal 70: 366-72.

Lowe, Pardee Jr., and Charles. W. Stansfield, eds. 1988. Second Language Proficiency Assessment: Current Issues. Englewood Cliffs, NJ: Prentice Hall Regents.

Magnan, Sally Sieloff. 1985. "From Achievement toward Proficiency through Multi-sequence Evaluation." Foreign Language Proficiency in the Classroom and Beyond. Ed. Charles J. James. Lincolnwood, IL: National Textbook Company. 117-46.

- 1986. "Assessing Speaking Proficiency in the Undergraduate Curriculum: Data from French." Foreign Language Annals 19: 429-38.

-. 1988. "Grammar and the ACTFL Oral Proficiency Interview: Discussion and Data." Modern Language Journal 72: 266-76.

-. 1991. "Just Do it: Directing TAs toward Task-Based and Process-Oriented Testing." Assessing Foreign Language Proficiency of Undergraduates. Issues in Foreign Language Program Direction. Ed. Richard V. Teschner. Boston: Heinle and Heinle. 135-61.

Marisi, Paulette. 1994. "Questions of Regionalism in Native Speaker OPI Performance: The FrenchCanadian Experience." Foreign Language Annals 27: 505-21.

Moeller, Aleidine, and Claus Reschke. 1993. “A Second Look at Grading and Classroom Performance: Report of a Research Study." Modern Language Journal 77: 163-69.

Omaggio, Alice C. 1986. "Classroom Testing.” Teaching Language in Context. Boston: Heinle and Heinle.

Raffaldini, Tina. 1988. "The Use of Situation Tests as Measures of Communicative Ability." Studies in Second Language Acquisition 10: 197-216.

Savignon, Sandra. 1983. Communicative Competence. Theory and Practice. Reading, Massachusetts: Addison-Wesley.

-. 1985. Evaluation of Communicative Competence: The ACTFL Provisional Proficiency Guidelines. Modern Language Journal 69: 129-34.

Shohamy, Elana. 1988. "A Proposed Framework for Testing the Oral Language of Second/Foreign Language Learners." Studies in Second Language Acquisition 10: 165-79.

SOPT Rater Training Manual for Form A. 1994. Washington, DC: Center for Applied Linguistics.

Stansfield, Charles W. 1994. "Developments in Foreign Language Testing and Instruction: A National Perspective." Teaching, Testing, and Assessment: Making the Connection. Ed. Charles Hancock. Lincolnwood, IL: National Textbook Company. 4367.

Stansfield, Charles. W., and Dorry M. Kenyon. 1992. "Research on the Comparability of the Oral Proficiency Interview and the Simulated Oral Proficiency Interview." System 20: 347-64. 
Thompson, Irene. 1996. “Assessing Foreign Language Skills. Data from Russian." Modern Language Journal 80: 47-65.

TOPT Test Preparation Kit. 1991. Preliminary ed. Washington, DC: Center for Applied Linguistics.

Tschirner, Erwin. 1996. "Scope and Sequence: Rethinking Beginning Foreign Language Instruction." Modern Language Journal 80: 1-14.

Tschirner, Erwin, and Kathy Heilenman. 1998. "Reasonable Expectations: Oral Proficiency Goals for Intermediate-level Students of German." Modern Language Journal 82: 147-58.

Underhill, Nick. 1987. Testing Spoken Language: A Handbook of Oral Testing Techniques. Cambridge: Cambridge UP.
Valdés, Guadalupe. 1989. "Teaching Spanish to Hispanic Bilinguals: A Look at Oral Proficiency Testing and the Proficiency Movement." Hispania 72: 392-401.

VanPatten, Bill. 1986. “The ACTFL Proficiency Guidelines Implications for Grammatical Accuracy in the Classroom." Studies in Second Language Acquisition 8: 56-67.

Villar, Susan McMillen, and Frances Meuser-Blincow. 1993. "Proficiency Requirement-Based and Nonproficiency Requirement-Based Second Language Programs: How Do Students Rate?" Foreign Language Annals 26: 49-62. 